\title{
A Knowledge Appropriation Model to Connect Scaffolded Learning and Knowledge Maturation in Workplace Learning Settings
}

\author{
Tobias Ley ${ }^{1}$ (D) $\cdot$ Ronald Maier ${ }^{2} \cdot$ Stefan Thalmann $^{3} \cdot$ Lena Waizenegger $^{4}$. \\ Kai Pata ${ }^{5}$. Adolfo Ruiz-Calleja ${ }^{5}$
}

Received: 26 July 2018 / Accepted: 29 July 2019 / Published online: 7 August 2019

(C) The Author(s) 2019

\begin{abstract}
When organizations create new knowledge and work practices as a reaction to challenges they face, they often have difficulty to adopt these new practices "on the ground". One of the reasons is that in these cases, individual informal learning and collective knowledge creation are often insufficiently connected. In this paper, we investigate knowledge practices that explain how new knowledge generated in the process of creating and adapting new practices is applied in work situations. We conducted 30 semi-structured interviews in five networks of organizations focusing on knowledge sharing in the German construction industry. Through a qualitative content analysis, we first identified five patterns of situations where individual and collective knowledge interact to implement new work practices. We detail these patterns with four knowledge maturation practices that explain how individuals contribute to collective knowledge development, and three scaffolding practices that explain how individual learning processes are facilitated through help seeking and guiding. Four practices of knowledge appropriation explain how knowledge is adapted and validated in concrete work situations. We combine scaffolding, maturation and appropriation practices into a model of knowledge appropriation that extends workplace learning research by offering a distinctive perspective on the practices that shape the interaction between knowledge creation and individual learning.
\end{abstract}

Keywords Workplace learning $\cdot$ Knowledge creation $\cdot$ Collective knowledge $\cdot$ Knowledge maturation · Scaffolding · Work practice knowledge · Construction industry

Tobias Ley

tley@tlu.ee

Extended author information available on the last page of the article 


\section{Introduction}

The important role of informal learning in workplace and professional development is now widely acknowledged. People learn in the context of their work often in a selfdirected way by exploring sources of information or by interacting with their colleagues or informal networks in order to extend their knowledge, solve problems at work or perform their everyday tasks. There is now wider consensus in workplace learning research that the challenge to study and support learning in authentic work situations needs different conceptualizations than the ones developed in the context of educational institutions (Billett and Choy 2013).

A number of models that we will review in the next section describe and explain processes that happen in the contexts of individual work, working teams, informal or formal networks and organizations. Despite a rich literature, there is a lack of workplace learning models on learning that happens through processes in which organizations develop new knowledge and appropriate such knowledge in new practices, that is models that combine perspectives on individual learning and collective knowledge creation. While we will present our review of related work in more detail in the next sections, one prominent example is the concept of communities of practice introduced by Lave and Wenger (1991). In our view this conceptualization rightly puts the emphasis on what makes workplace learning special: the socially situated and often informal character of interchange among members of a community from a particular enterprise who also lead new members to adopt its practices through legitimate peripheral participation. However, the focus of research on communities of practice has to a lesser degree tried to bring to light how the community challenges its assumptions, develops its collective knowledge base further, and how then individuals appropriate this knowledge in concrete working situations.

When organizations develop new work practices, the community is yet to develop relevant knowledge to implement and so there is no teacher who "knows the answer", and individual learning goals remain unclear. Individual learning is tightly integrated into knowledge creation of teams, networks and the organization - a process we call knowledge appropriation.

As an example taken from the present study, consider the introduction of a new energy norm for low-energy houses within a regional network of construction companies. Employees from several companies form a community around the shared enterprise of sustainable construction techniques. The members of the community work together, develop knowledge needed and apply the new techniques to fulfill the requirements for certification of these techniques. New and certified construction techniques and work practices are the results of this collaboration. However, the widespread adoption of these techniques is mainly impeded by missing knowledge "on the ground", that is a lack of know-how about how to apply the techniques and use the materials in concrete circumstances.

In such situations, new work practices need to be developed. That is, socialhistorically created behavioral patterns, routines, or ways of working in the form of materially mediated, embodied work activities (Paavola and Hakkarainen 2014). However, many companies struggle to develop those new practices across all construction teams within the company and between the professions. Also, there is a challenge to ensure that employees share experiences about the implementation in a particular 
context across teams. Developed knowledge needs to be adapted to local requirements (Schäper and Thalmann 2015), and there is pressure on workers to adapt their knowledge and practices (Billett and Choy 2013).

From a workplace learning perspective, it has now been recognized that employee engagement in such innovation processes is critical (Lundkvist and Gustavsson 2018). However, as the example above suggests, the development of new knowledge and work practices spans learning in and across different social entities (the individual worker, the group or team, the organization or cross-organizational networks). In this paper, we explore the relationship between models of individual and collective workplace learning, in order to identify and systematize the informal learning practices that can be observed in the context of collective knowledge creation processes. This should enable us to better understand "how such collaborative processes can best occur, what makes them effective and what are the limits of their efficacy" (Billett and Choy 2013, p. 268).

We explore these learning and knowledge creation practices in the German construction industry. This industry is characterized by a constant need to adapt their work practices as a result of regulatory changes, innovations in construction techniques and technologies. Furthermore, the adaptation of knowledge to local circumstances is particularly important due to the diversity of physical work settings such as different construction sites. Insights we gained from conducting 30 semi-structured interviews lead us to propose a model of knowledge appropriation that identifies practices of individual and collective learning and how new knowledge is appropriated in work practices.

\section{Knowledge Creation as an Interaction of Individual and Collective Knowledge}

In the following section, we discuss models of knowledge creation and workplace learning to review the role of individual and collective learning (Knowledge Creation and Workplace Learning Theories). We then review practices of knowledge maturation and scaffolding (Knowledge Maturation and Scaffolding), and conceptualize knowledge appropriation practices in order to explain how newly created knowledge is applied in concrete work situations (Knowledge Appropriation). Finally, we summarize these conceptualizations and focus our investigation with the help of three research questions (Research Questions).

\section{Knowledge Creation and Workplace Learning Theories}

The idea that individual and collective knowledge is tightly interrelated when new knowledge and work practices are created has been widely acknowledged. Various knowledge creation processes transform knowledge across individual, group, organizational and cross-organizational levels (Crossan et al. 1999; Kogut and Zander 1992; Nonaka and Takeuchi 1995; Nonaka et al. 2006). The activity of knowledge creation has been conceptualized as a social process that transforms knowledge from the individual level into everwider communities of interaction that could eventually cross organizational boundaries (Nonaka and Takeuchi 1995). According to Crossan et al. (1999), processes 
of knowledge creation exist on three levels: i) intuiting and interpreting (individual level); ii) integrating; and iii) institutionalizing (collective level).

Organizational knowledge creation theories address these knowledge conversion processes, but they focus to a lesser extent on how new knowledge is adopted in day-today tasks. One of the reasons for this gap may lie in the fact that knowledge creation models are somewhat disconnected from the models of learning at work which consider how knowledge is acquired and applied in work practices (Ellström 2010), how individuals generate new knowledge and apply it while working with or alongside colleagues (Engeström 2001), and how individuals participate and reflect about the actual implementation of new knowledge (May and Finch 2009).

A range of social and sociocultural learning theories (e.g. Rogoff 1995; Vygotsky 1978) consider individuals as developing personal expertise through guided experience with experts or more advanced peers who help them internalize cultural tools and practices. These theories have motivated a range of recent workplace learning theories to explain how learning at the workplace is guided by experienced coworkers or indirectly by knowledge artefacts (Billett 2002).

So, both in knowledge creation theories as well as in social learning theories, interaction between individual knowledge and collective knowledge is important (see also Kimmerle et al. 2010, and Paavola and Hakkarainen 2014). Whereas in knowledge creation theory, the concern is on creation of new knowledge from individuals to collective levels, in sociocultural learning theory collective knowledge is mediated by individuals during their learning process. Finding out, how these processes interact in workplace learning situations is the goal of this paper.

We focus our empirical investigation and the theorizing on two types of knowledge practices: First, knowledge maturation practices (Maier and Schmidt 2015) allow us to describe collective learning processes in organizations, or how individuals contribute to knowledge creation. Second, scaffolding practices (Tammets et al. 2013; Wood et al. 1976) allow us to understand how individuals engage in these collective learning processes and how this is facilitated for individuals in organizations in case they seek support. In "Knowledge Maturation and Scaffolding" section we will review these practices in more detail.

We then introduce the concept of knowledge appropriation which we assume underpins both knowledge maturation and scaffolding when new knowledge is created and distributed in the organization. This concept describes how knowledge is put to use locally that has been developed collectively in a sociocultural learning process. We aim to identify the knowledge appropriation practices in concrete working situations that sustain this kind of learning in "Knowledge Appropriation" section.

\section{Knowledge Maturation and Scaffolding}

\section{Knowledge Maturation Practices}

Knowledge maturation comprises organizing work around knowledge artefacts. New knowledge in organizations or cross-organizational networks is created as the common object of activity and is shared in the forms of instruments, procedures, methods, policies or other forms of work organization. Knowledge artefacts are materially 
embodied entities that are worked on in various external memory fields (Donald 1991) and activity systems (Engeström 2001). Passing the knowledge artefacts from one social entity (individual, group, collective) to another requires its remediation as a central practice (Paavola and Hakkarainen 2014), and allows these social entities to improve and extend that knowledge by refinement and the inclusion of new properties. Thus, knowledge artefacts serve as the emergent interactional resources (Stahl 2013) that mediate between individual learning, group cognition and organizational knowledge building (Nardi 1996; Paavola and Hakkarainen 2014). This leads to changes in the format of knowledge, for example, from implicit to explicit, from practiced behaviors to verbally or visually communicated experiences and to written documents (Kogut and Zander 1992).

Maier and Schmidt (2015) distinguish specific knowledge maturation practices at the individual, group and organizational levels of goal-directed collective learning. Innovative knowledge emerges initially at the individual level. When individuals face new situations and problems, they start to experience, explore and experiment with new ideas. At the group or community level, employees share the discovered knowledge with other professionals to validate it, to seek collective recognition or ask for advice. The knowledge stays distributed in the discussions between diverse professionals, but negotiations enable them to develop a shared vocabulary and a common ground that substantiates this knowledge. To reach beyond the social group, knowledge transformation is required at the organizational or collective level where the focus is to cocreate common artefacts. Transformation means that knowledge is restructured and decontextualized to ease the transfer from the originating community to other collectives. To enable such further outreach, employees formalize knowledge in a way that is easier to understand by others or put to practice in a pilot. Those experiences are incorporated into the knowledge artefacts to prepare for wider roll-out. Knowledge gets a stable place and is institutionalized, either as part of formal training plans, or as company-wide implementations. Finally, knowledge can mature beyond the scope of companies where external bodies standardize or certify knowledge to establish comparability and compliance.

\section{Scaffolding Practices}

Having a closer look at knowledge maturation practices in the previous section, a special emphasis was put on how knowledge artefacts emerge in the knowledge maturation process. Sociocultural learning theories assume that culture as a product of collective learning provides cognitive tools for individuals and groups for development of knowledge. These cognitive tools can also scaffold the learning of individuals (Wood et al. 1976). In workplace learning research, scaffolding has been considered in theories of cognitive apprenticeship (Smith 2003) and self-regulated learning (Littlejohn et al. 2012; Siadaty et al. 2016). Appropriate structures (scaffolds) may guide those who initially seek help to enhance individual, group or collective learning. Such guidance fades out as the individual, group or collective becomes capable of solving certain problems. Scaffolding thus incorporates guidance and sensemaking to establish common understanding of the problem and solution between those who require help and those that support them. Scaffolding incorporates various prompting requests, negotiation and validation for developing shared understanding. Knowledge 
is used as a guidance structure that offloads cognitive activity and can thus facilitate learning of individuals, groups and collectives (Hollan et al. 2000). While initially scaffolding was focused on an interaction between a learner and a more capable peer (Wood et al. 1976), more recently dynamically accumulated knowledge in groups or collectives have been conceptualized as scaffolds (Barrett et al. 2004; Tammets et al. 2013; Twidale 2005) towards which individuals adapt.

Knowledge Appropriation Knowledge maturation and scaffolding can be seen as two complementary processes of learning as visualized in Fig. 1. On the one hand, knowledge maturation focuses on the collective agency of an organization or other social entity. It describes the goal-directed character of how knowledge is further developed in that entity. Scaffolding, on the other hand, focusses on the individual agency of the learner and the way individuals seek to advance their knowledge and expertise in a self-directed and social process.

These two processes become visible in concrete work situations and contexts. For example, the new energy norm mentioned in the introduction triggered collaborations in a work team to develop new construction techniques. At the same time, these new techniques were tested at construction sites where learning occurred and new techniques were experienced. In these situations, individual and collective knowledge interact to create new knowledge and work practices. The need to create new work practices is often triggered by outside forces, or by concrete problems encountered in the field, the new energy norm in our case example.

While there is clarity of what practices are connected to knowledge maturation and scaffolding (see "Knowledge Maturation and Scaffolding" section), it is less clear what exactly happens in those situations at the workplaces and how knowledge is mediated and applied. For example, how does the work team become aware of others' experiences with the new techniques, or how do individuals apply the newly developed practices in their contexts?

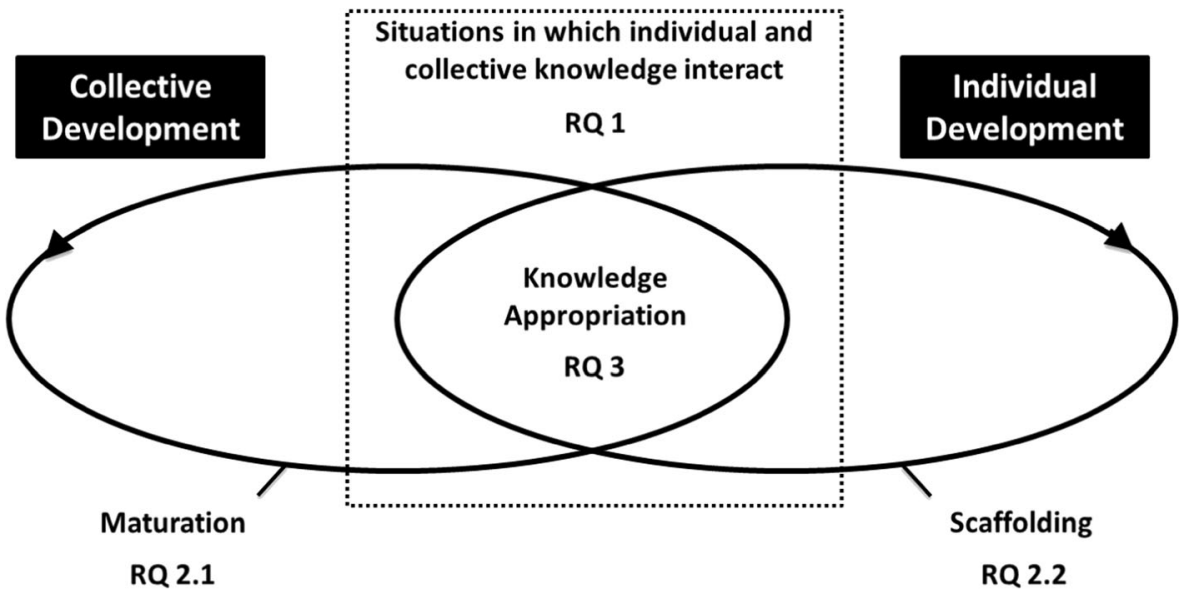

Fig. 1 Knowledge appropriation to connect maturation and scaffolding 
In both, knowledge maturation and scaffolding practices, knowledge artefacts play a central role. Through both these practices, knowledge is mediated between individuals, groups and collectives, leading to a two-way adaptation between these entities: individuals' learning is shaped by being part of teams and collectives, while they also contribute to the development of knowledge. Knowledge artefacts have been key in sociocultural learning theories (Billett and Choy 2013), and they can also be considered key when knowledge is applied across different contexts. In this case, working and learning is mediated by knowledge artefacts. We employ the term "knowledge appropriation" to describe the situation where knowledge that has been created is applied in a different context and in concrete working situations. We chose the term appropriation, as we see some relation to the concept of "participatory appropriation" introduced by Rogoff(1995).

Research Questions Summarizing from the above, we formulate the following three research questions. The first one focuses on situations in which creation of new work practices can be observed ("Knowledge Creation and Workplace Learning Theories" section).

RQ1: What are the work situations in which individual and collective knowledge interact in the creation of new work practices?

The second question then focuses on the collective and individual learning processes that can be evidenced in these situations ("Knowledge Maturation and Scaffolding" section):

RQ2: What are the knowledge maturation and scaffolding practices through which collective knowledge is created and individuals receive support when engaging in those new practices?

The third research question focuses on knowledge appropriation as an emerging theoretical construct ("Knowledge Appropriation" section).

$\boldsymbol{R Q}$ 3: Which are the knowledge practices that explain the appropriation of knowledge in concrete work situations?

\section{Method}

The goal of the study was to explore the interaction between individual and collective knowledge in workplace settings. We aimed to find evidence for different knowledge practices in the German construction industry in situations where collective knowledge is created and then appropriated for solving local problems. We focused our investigation on the interaction between knowledge maturation, scaffolding and appropriation practices and applied a two-step exploratory research approach involving organizations in the construction sector in Germany (see Fig. 2 for an overview of the study design). For conducting the interviews, we were able to draw on five construction industry networks in the Northern part of Germany. The reasons for choosing these networks to recruit participants was that they are knowledge creation networks and active in adapting new knowledge to the local circumstances, so that they could help us identify 
First round interviews

7 initial interviews in 5 networks

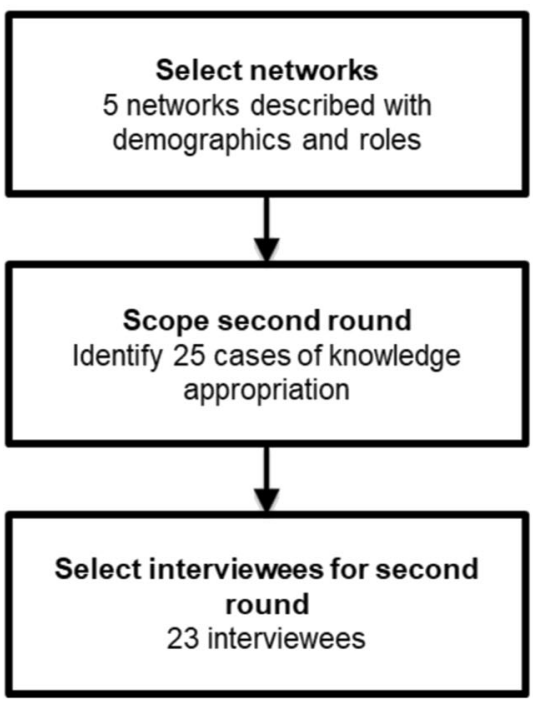

Fig. 2 Process of data collection and analysis
Second round interviews

23 follow-up interviews in the 5 networks

Extract patterns of knowledge appropriation (interaction of individual and collective knowledge) 5 patterns extracted

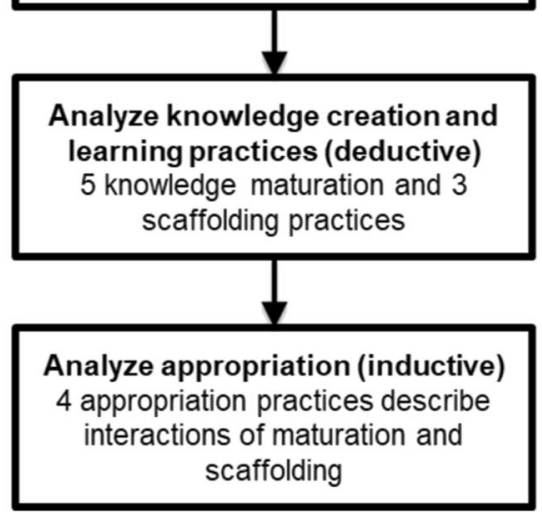

relevant cases for appropriation. Being able to draw on networks also gave us the opportunity to focus on cross-organizational collective knowledge which is significant from a knowledge maturation perspective. Further, this study was part of an international research project ${ }^{1}$ which facilitated the access to the participants due to previously agreed on collaboration commitments.

In total, 30 semi-structured interviews were conducted between March 2014 and June 2015.

Individual interviewees were recruited from the selected networks for each data collection phase.

Table 1 gives an overview of the networks and the respondents.

In the first round of our study, we conducted seven face to face interviews, which took approximately two hours each. The goal was to get an initial understanding of the networks and to identify people who are actively engaged in innovation adoption, and who we could contact for the subsequent second-round interviews. In the interviews from the first round, we identified initial cases of how individuals and organizations appropriate knowledge, and gathered examples of how knowledge maturation and scaffolding evolve at the workplace. This helped us guide the second round interviews.

In the second round, we conducted 23 interviews via telephone or video conferencing, each of which took approximately one hour. The goal was to investigate appropriation practices at the workplaces that happened as a result of individual and collective learning.

\footnotetext{
${ }^{1}$ The purpose of the project Learning Layers (EU FP7, 2012-2016, http://learning-layers.eu) was to study and support workplace learning practices to scale informal learning in Construction and the Health Care domain.
} 
Table 1 Networks from which respondents in two rounds of interviews were drawn

\begin{tabular}{|c|c|c|c|}
\hline Network & Short description & $\begin{array}{l}\text { Interviewees in } 1 \text { st } \\
\text { round }\end{array}$ & $\begin{array}{l}\text { Interviewees in } 2 \text { nd } \\
\text { round }\end{array}$ \\
\hline N1 & $\begin{array}{l}\text { - Regional industrial and labor association } \\
\text { for the construction sector } \\
\text { - } 270 \text { construction companies } \\
\text { - Foundation } 2012 \text { (an earlier association } \\
\text { was already founded around } 1900 \\
\text { - Main goal: lobbying and localization of } \\
\text { innovations }\end{array}$ & $\begin{array}{l}\text { managing director and } \\
\text { chief education } \\
\text { manager of the } \\
\text { network }\end{array}$ & $\begin{array}{l}1 \text { lawyer, } 2 \text { company } \\
\text { owners, } 2 \\
\text { managing } \\
\text { professionals }\end{array}$ \\
\hline N2 & $\begin{array}{l}\text { - Nationwide society of individuals and } \\
\text { organizations who wish to foster building } \\
\text { with bales of straw } \\
\text { - } 130 \text { companies and individuals with the } \\
\text { focus on straw bale building } \\
\text { - Foundation: } 2002 \\
\text { - Main goal: innovation leader in the field }\end{array}$ & $\begin{array}{l}\text { board member of the } \\
\text { network and architect }\end{array}$ & $\begin{array}{l}3 \text { architects, } 1 \text { master } \\
\text { carpenter, } 1 \\
\text { company owner }\end{array}$ \\
\hline $\mathrm{N} 3$ & $\begin{array}{l}\text { - Regional network for sustainable building } \\
\text { managed by a regional center for } \\
\text { sustainable construction } \\
\text { - <30 companies with focus on sustainable } \\
\text { construction } \\
\text { - Foundation: } 2011 \\
\text { - Main goal: innovation leader in the field }\end{array}$ & $\begin{array}{l}1 \text { architect, } 1 \text { board } \\
\text { member of the } \\
\text { network }\end{array}$ & $\begin{array}{l}1 \text { employee, } 3 \\
\text { company owners }\end{array}$ \\
\hline N4 & $\begin{array}{l}\text { - Online network of organizations who build, } \\
\text { renovate, or are interested in half-timbered } \\
\text { buildings } \\
\text { - } 1600 \text { professionals and novices in } \\
\text { half-timbered buildings } \\
\text { - Foundation: } 2002 \\
\text { - Main goal: networking, co-development } \\
\text { of solutions and innovations }\end{array}$ & $\begin{array}{l}\text { founder of the network } \\
\text { and network } \\
\text { manager }\end{array}$ & $\begin{array}{l}3 \text { company owners, } 2 \\
\text { architects }\end{array}$ \\
\hline N5 & $\begin{array}{l}\text { - Regional association of electricians } \\
\text { - } 92 \text { electric companies } \\
\text { - Foundation: around } 1930 \\
\text { - Main goal: lobbying and localization } \\
\text { of innovations }\end{array}$ & $\begin{array}{l}\text { regional network } \\
\text { manager }\end{array}$ & 4 company owners \\
\hline
\end{tabular}

The interviews were audio-recorded and transcribed in verbatim form. Raw transcripts were checked for accuracy and reliability. We analyzed the transcripts by applying an informed inductive coding procedure carried out with the help of the software Atlas.ti. This procedure allowed us to identify categories from the material itself as well as existing concepts from the literature which we used as codes for the data analysis process (Mayring 2014). Two members of the author team were engaged in the coding process and held regular meetings to discuss the meanings of the codes in the codebook and the emerging patterns that evolved from the data. The process of data collection and analysis is visualized in Fig. 2.

The purpose of the first part of the study (left side in Fig. 2) was scoping of the research both in terms of the situations of knowledge appropriation (where individual and collective learning interacted), as well as the respondents to be selected for the in- 
depth interviews. In the first round of interviews, we identified 25 cases of situations, such as "ask network members in WhatsApp group" or "jointly develop a solution for foam concrete" from our studied networks. In the second part of the study (right part), we then analyzed the additional data (from the interviews in the second round) to identify patterns of knowledge appropriation and established five top-level code categories such as "adapt knowledge to local needs", or "co-create solutions in face to face meetings" (see Table 2, and Boud and Middleton (2003) for a similar methodological approach).

Moreover, we analyzed these five patterns in terms of the knowledge practices that contributed to knowledge creation and learning in these situations. We used a deductive

Table 2 Patterns of knowledge appropriation (interaction between individual and collective learning)

Pattern Example case (C) from networks (N)

\footnotetext{
1 Request help to solve work C1.1: Ask network members on WhatsApp (N1) problems

C1.2: Call (phone) people known from network events (N2)

C1.3: Send pictures via e-mail to network members (N3)

C1.4: Post a picture and questions in the online forum (N4)

C1.5: Call (phone) a network member (N5)
}

2 Share knowledge to initiate C2.1: Post new insights in WhatsApp group (N1) discussion

C2.2: Present new insights from a network event in another country (N2)

C2.3: Share details about a new construction material (N3)

C2.4: Post a success story for an uncommon case (N4)

C2.5: Send details about new guidelines via the network's newsletter (N5)

3 Co-create solutions in face-to-face meetings

4 Adapt knowledge to local needs

5 Formalize knowledge as a shared activity

\section{C3.1: Jointly develop a solution for foam concrete (N1)}

C3.2: Jointly develop a clay plaster to fulfill the fire regulations (N2) C3.3: Jointly develop solutions to fulfill a new air tightness value for passive houses (N3)

C3.4: Jointly experiment how to apply historic construction methods (N4)

C3.5: Jointly experiment how to use new construction material (N5)

\section{C4.1: Meet for breakfast to discuss new regulations (N1)}

C4.2: Discuss how to apply new construction techniques from different countries as part of a formal network event (N2)

C4.3: Discuss about the implications of a new passive house norm at a network event $(\mathrm{N} 3)$

C4.4: Create a new discussion channel to discuss the applicability of a construction method for a regional historic type of house (N4) C4.5: One of the network members presents a new ISO norm and the members collaboratively discuss at a network meeting (N5)

C5.1: Jointly describe the requirements for a new law in a national legal consultation process $(\mathrm{N} 1)$

C5.2: Jointly work on the certification for straw bale houses (N2)

C5.3: Jointly develop an exhibition (N3)

C5.4: Jointly create best practices shared as feature articles (N4)

C5.5: Jointly create checklists (pocket cards) about how to use certain machines (N5) 
approach to identify maturation and scaffolding practices from literature (see "Knowledge Maturation and Scaffolding"). Finally, the interactions between maturation and scaffolding practices were analyzed in an inductive process of comparing across the cases and drawing on related literature, finally evidencing knowledge appropriation practices in each of the cases.

\section{Findings}

\section{RQ1: Situations where Individual and Collective Knowledge Interact}

Our analysis of the interview data resulted in the identification of five patterns describing the interaction between the individual and collective learning. Table 2 gives an overview of the five patterns together with example cases from each of our five networks. The networks are the unit of data collection as the collective can also be represented on sub-units of networks. Below, we describe the five patterns of situations and illustrate each of them with a case example taken from one of the networks (bold in Table 2).

\section{Pattern 1: Request Help to Solve Work-Problems}

We found that workers use mobile applications such as WhatsApp to request help from colleagues. Their requests motivate their peers to share knowledge and raise awareness for new knowledge. Important here is the adaptation of knowledge to their own situations and validation of their actions. Finally, the result is shared with the group or the whole network.

In case $\mathrm{C} 1.1$, a foreman reported about an urgent problem with a new product during his work that needed to be solved as quickly as possible (N1/I4): "Well, I come across situations, where I simply have to do something. I have to react. I cannot say, we stop now. I must react now ". The foreman and his former colleagues, interact virtually in a WhatsApp group which is used for asking questions and giving advice in case somebody has a problem during work and seeks help or to share new insights from their own work. (N1/I4): "Most of the time I use WhatsApp. We have a special group, consisting of old friends from the network's training center, where we post pictures with questions when we seek help. Additionally, you can have a look at your phone and check if there are any interesting updates."

As the members of the WhatsApp group attended the same training center operated by the network, the foreman and his friends share part of their professional training and background. They have built strong relational ties and social capital during their professional training. The foreman initiates the help seeking process by sending a picture of the problem with the new product to one of his former classmates who is online on WhatsApp and asks if he or she experienced similar problems or has an idea on how to solve it. (N1/I4): "If I am facing a concrete problem and I do not know how to solve it, then I will check who is online and available to contact. Then I will send it to this person and try to receive an answer as fast as possible“. Thee questions also raised awareness. As workers always have their smartphones with them, they can easily take pictures or videos of the construction sites and send them to their peers to jointly cocreate a solution to apply the new product in their local work context. 


\section{Pattern 2: Share Knowledge to Initiate Discussions}

We also found evidence of this pattern in all networks. Here, one network member identifies relevant knowledge about a new product and shares this with the group. Interested network members start a discussion on how to apply the product in their own work contexts and frequently co-create new knowledge to form novel solutions.

In C2.1 WhatsApp is used as a knowledge sharing platform for spreading innovative working procedures. For example, a foreman reported that he had a construction project where he used a new and very innovative solution (N1/I4): "If I have found a solution for some specific problems then I post it and add some relating pictures, because it is interesting for all of them". Thus, he posted some pictures and provided some data (like soil density) and invited his colleagues to pass by and have a closer look at his project (N1/I4): "Then it works like that: the people who are interested say that they will come by and have a look at what we are doing here". However, he does not compile the best practice in a formal way.

\section{Pattern 3: Co-Create Solutions}

Most of the innovations in the construction sector are introduced by manufacturers of machinery and construction material. Hence, the companies have to assimilate new knowledge and find out how to apply those in their context. Because the innovations are relevant for many network members they often hold physical meetings at construction sites of the early adopters to jointly experiment and co-create solutions. In this way, they adapt the innovation to the local needs through joint experimentation and sometimes they write lessons learned and share it with their peers.

Craftsmen highlighted the importance of local networks and the possibility to physically meet each other to discuss new innovations, e.g. new materials machines or characteristics of construction sites (C3.1). In the collaborative learning phase, people discussed and reported about their hands-on experiences during the meeting to find a solution and create a shared understanding about the innovation (N1/I4): "First, we went to the place, where the problem occurred and shared our thoughts regarding possible solutions". A foreman reported about a very difficult situation where his team tried to build a street with foam concrete and they experienced issues following two days of heavy rain. (N1/I4): "Then I include my whole crew. I have seven people in my team. I include all of them and we sit together and debate what we could do. There are also some older ones, who have a lot of experience and do the job for years already, so they know what makes sense in a specific situation".

The team decided to meet and to develop a solution collaboratively, and the bestfitting solution was then adopted. In this case, it was important to develop a shared understanding of the context in which the new technique was applied to avoid risks on the construction site. They document the solutions using pictures and videos to share their experiences.

\section{Pattern 4: Adapt Knowledge to the Local Needs}

One of the major purposes for organizations to join networks is to bundle resources to appropriate knowledge which affect all members. For such cases all networks had 
appointed delegates. These delegates raise the awareness of the network members and guide their attention towards new knowledge in the field, before they jointly discuss the implications. They then discuss how to adopt the knowledge to their local contexts or outsource to experts. Finally, a formal document is created and shared with all network members.

One of these issues is the release of new legislative procedures. In case C4.1, a lawyer employed by the network held presentations about new legal regulations that affect the construction domain. She initiated group discussions to gather opinions on how to interpret the new legal situation. (N1/I1): "I decided that this is a very crucial topic and therefore I wanted to see how the participants see these new legal regulations. Therefore, I had to present it to them first without coming up with legal advice about it".

As the effects of rules and regulations are not completely predictable before they are applied in practice there is always more than single interpretation: "That was about the implementation of a digital trip recorder. There was an exceptional rule and its interpretation, and a lot of different opinions were on the market because engineers dealt with this problem as well. The reason for all this were three EU regulations, two German laws and another German regulation." (N1/I1) Following discussions in the group, they created a holistic picture of the regulation with all of its implications for the members. As a final step the lawyer summed up the outcome of the discussion and created a document which was sent to all. "Let's take the example of the trip recorder again. I wrote a document and around 10.000 vehicles drive around with this description by now. That is the document of the [N1], but I also send this to the construction firms, the ministry, the industry control office, and the national network in Berlin." (N1/I1).

\section{Pattern 5: Formalize Knowledge as a Shared Activity}

At some point the knowledge that is newly created needs to be formalized in order to be effectively applied. This formalization is a resource intensive procedure. Hence the members of the network bundle their resources and involve external expertise to perform this task. They distribute the work and members explore the domain. They negotiate in meetings and collaboratively create solutions to finally describe their knowledge in a formal and decontextualized way.

This practice was applied in a joint project of the network that focused on straw bale houses (C5.2). The group realized that certification was required to build such new innovative houses and they decided to develop the procedure as a group given the effort for standardization was substantial.

(N2/I6): "In the beginning we got the permission to build the houses for each case separately. We then saw, if we want to do this on a bigger scale, we need to found a network with experts to work on these topics". They co-created several knowledge artefacts by sharing experience and adapting the construction processes and plans according to regulations in order to obtain the certificate they needed. They created a model area with straw bale houses and 300 people came to contribute to the project. Additionally, the network tried to work together with experts from a similar network in France. With the help of a university laboratory, the network managed to deliver the required evidence to demonstrate that the newly created innovation fulfilled the requirements of the certification agency. 


\section{RQ 2: Maturation and Scaffolding Contribute to Individual and Collective Learning}

Taking the patterns as a backdrop for our further analysis, we turn to the question on how knowledge creation and learning practices contribute to individual and collective knowledge. The case examples presented above confirm the important role that individuals, groups and collectives have for creation of new work practices. The development of individual expertise to deal with problems is key, but professionals usually involve various persons in their direct social proximity as well. So workers are members of a team or several teams that collaboratively solve a problem and therefore learn together (as in C3.1), and they draw on their own personal network for advice or help (as in C1.1). Sometimes groups or collectives themselves become the focus of learning. The working group on new laws and norms (C4.1) is one example, and the network of sustainable construction that created a new specification of how to build straw bale houses (C5.2) is another.

We suggested that knowledge maturation and scaffolding practices play an important role in mediating knowledge between the individual and the collective. We found evidence for the three maturation practices share, co-create and formalize and the two scaffolding practices seek help and guide in all five networks that we studied. For example, in $\mathrm{C} 1.1$ and $\mathrm{C} 2.1$, seeking help is initiated by posting problems in the WhatsApp group using pictures and videos to find suitable solutions for a concrete work problem. In C4.1, professionals seek not just the help from an expert but also the opinion of other members of the network in order to solve current problems and complement their own knowledge. When sharing knowledge in C5.2, all experts are engaged in one common project and people share new insights from visits with the group, and these are also discussed so that individual learning is taken up to the level of collective learning.

Co-creation was observed in C3.1 where professionals used local networks and virtual networks to solve work problems as a group, or in $\mathrm{C} 4.1$ when a work group to develop basic knowledge of judicial affairs was founded. Also in C4.1, participants agreed on a structure to organize their knowledge exchange as a group and developed guidelines for their employees at the individual level. The latter are examples of guiding practices that rely on establishing structures that can enhance individual or collective learning. Finally, formalization was observed when recommendations were written up for a wider number of employees (such as in C4.1), or when the results of the experimentation in C5.2 first had been discussed in the group and were then formally written up for the wider community.

\section{RQ 3: Knowledge Appropriation Practices to Connect Individual and Collective Learning}

The maturation and scaffolding practices described in the previous section neither happen in isolation from each other, nor do they follow a linear sequence. Instead, there are a number of feedback loops that can be observed. We think that these feedback loops are evidence of attempts to appropriate knowledge in concrete work practices on the individual and collective level. For example, when the implications of a new law had been discussed and understood (as in C4.1), it was still not certain that workers on the construction site followed these implications. The challenge then 
becomes how to enable construction workers to appropriate that particular knowledge on the construction site. Similarly, from a collective perspective, when particular aspects are experienced on site, it is not for certain that a working group tasked with finding more generalizable solutions is conscious of these experiences and go on to appropriate them as a common practice.

When observing these situations, it seemed they could be described as a process of pattern identification, matching and application. Patterns can be proven solutions to a class of problems, or simply certain approaches to understand and conceptualize typical problems in a domain. They could be understood as "patterns of meaning" (Ley et al. 2016) which are socially constructed, often mediated by artefacts, culturally transmitted and individually learned. Patterns are applied and developed in a process of assimilation and accommodation of individual and collective learning (Kimmerle et al. 2010). Individual expertise is a result of the acquisition of these patterns of meaning, and their skillful application.

While the learning of patterns is a latent process, it manifests itself in certain knowledge appropriation practices that can be observed. For example, shared artefacts are used to spread knowledge to others and interconnect individual and collective learning. However, the existence of these artefacts alone is not sufficient for knowledge appropriation to be successful. First, individuals and collectives need to be aware of those artefacts (create awareness). Also, appropriation into work practices needs them to build shared understanding (e.g. through participation and negotiation; Wenger 2004; Paavola et al. 2004). These negotiation processes also entail a form of reassurance to determine whether some knowledge is valid and should be adopted (validate). Finally, decisions have to be made whether knowledge is applicable in a particular context and has to be adapted to local conditions (adapt).

Next, we summarize evidence of the knowledge appropriation practices we gained through the interviews.

\section{Create Awareness}

The first prerequisite of appropriation is that there is awareness of some new knowledge, new solutions or experiences that could be applicable in a particular situation. A lack of awareness implies that the 'wheel is reinvented', existing guidelines are not followed, or experiences of individuals are ignored when a new standard is established. Social media is often used to create awareness given its interactive nature and its support to access and share data instantly. In C2.1, a foreman who was working on a new construction project posted the new solution and reported instantly about the details of the procedure in his WhatsApp group using photos and text. He raised the awareness in his colleagues while still working on the solution or shortly afterwards.

\section{Build Shared Understanding}

Negotiation and grounding happen between peers in scaffolding when they start a conversation and try to generate and maintain a shared understanding of the problem situation. Similarly, in the knowledge maturation model, negotiation happens in an attempt to explore the transferability or generalizability of particular knowledge to other 
contexts and is therefore a key process to lift knowledge to the next maturation stage. The case C3.1 covers two negotiation processes. The first one takes place between the construction worker and his superior on the phone and the second one among the construction worker, superior, engineers and other work colleagues on the construction site. While the purpose of the one-to-one negotiation between the superior and the construction worker was to get the opinion of the more knowledgeable peer, the purpose of the second negotiation on site was to collaboratively develop a shared understanding of the problem and co-create a solution. They discussed several alternatives, talked about their applicability and made sense of their opinions.

\section{Adapt}

Applying a solution to a new situation always requires some form of adaptation to the local context. It is a matter of de- and re-contextualizing knowledge and exploring which conditions can make the application successful and whether and how the solution can be adapted. In C4.1 the lawyer introduces new judicial legislation and the CEOs of the construction firms try to develop solutions to best implement these new regulations in their context. C5.2 shows the formation of the straw bale house network and how the participants started out working together, sharing their knowledge and accessing knowledge about straw bale techniques from other networks. To get the required permission they adapted the processes and materials, especially from the French network to comply with the local regulations.

\section{Validate}

Applying new solutions always entails a certain amount of risk. The appropriation process therefore has to establish some form of validation for a solution. This could happen through gathering experiences, getting social support or approval or getting authorization from some authority. The validation of one's own decision and opinion became a common pattern in the construction sector which is supported by common use of mobile ICT on the construction site. Employees tend to validate their opinion not just because it is often enforced by the organizational code of conduct but also to reassure themselves. As they assume increasing responsibilities, they also attempt to share these responsibilities with others. As part of C3.1, the foreman called his superior to validate the decision of the team when they were facing the challenge of a flooded road.

While the foreman in C3.1 had to validate his decision by a superior and therefore comply with the reporting hierarchy, the organizations involved in the straw bale network validated their opinion for mutual benefit and reaching a common goal. As such validation does not only happen between different hierarchical levels but also in a collaborative way, in this case at the network level.

\section{Synthesis: Knowledge Appropriation Model}

Figure 3 presents our emerging understanding of how individual and collective perspectives of learning are interconnected through knowledge appropriation practices. On the left side, we cover collective learning through sharing, co-creating, formalizing and standardizing as maturation practices. On the right side, individual learning is 


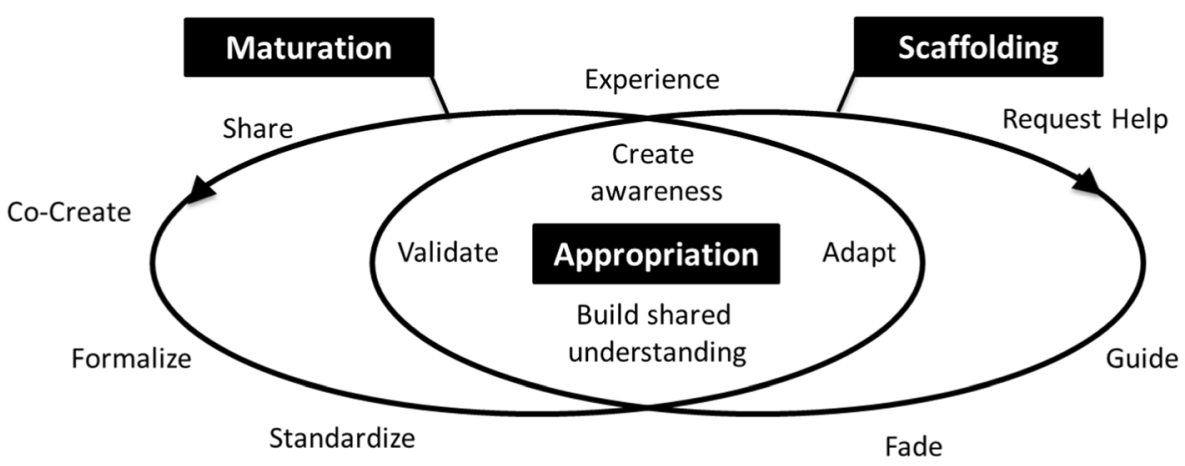

Fig. 3 Knowledge appropriation model to connect knowledge maturation and scaffolding

covered through scaffolding practices of requesting help, guiding and fading. Evidence for these come from literature as well as from the interviews reported in the previous sections "RQ1: Situations where Individual and Collective Knowledge Interact" to "RQ 3: Knowledge Appropriation Practices to Connect Individual and Collective Learning".

\section{Discussion, Implications and Limitations of the Model}

\section{An Emerging Model of Practices of Knowledge Appropriation}

In this paper, we have addressed several open issues in workplace learning research. As Billett and Choy (2013) note, despite a long history of research in workplace learning as a social practice, it is not yet fully understood how "informed social partners assist the development of individuals' knowledge" (p. 267) in workplace settings, and how "the relationship between personal and social contributions to learning" (p. 270) plays out in this regard. The knowledge appropriation model assumes that this engagement is a natural side effect of what happens when groups and organizations create new knowledge, and that collaborative processes of knowledge creation are tightly coupled with individual knowledge advancement. The model we propose makes these practices explicit and allows them to be investigated further. For example, we have studied cocreation practices when secondary school teachers introduce innovations in the classroom (Leoste et al. 2019).

Close observation of knowledge maturation and scaffolding activities in several cases, has led us to encounter further practices that we see as a prerequisite for successful knowledge maturation and scaffolding and which we have termed knowledge appropriation practices. Certainly others before us have described practices similar to the ones we found. For example, what we have called building of shared understanding is an important concept in the "negotiation of meaning" (Wenger 2004), or the "negotiation of intersubjectivity" (Billett and Choy 2013). Billett and Choy (2013) also mention the important process of adaptation when knowledge is transferred to new contexts. We found creating awareness and especially the practice of validation to be crucial in our cases, as nowadays knowledge seems to be abundant, but difficult to access and maybe even more difficult to validate. 
Others have also conceptualized the interaction of collective and individual knowledge in organizational learning. We contribute to the model of Kimmerle et al. (2010) by explicating the knowledge practices by which contributions to individual and collective knowledge happen. The "Charting Model" (Littlejohn et al. 2012) is conceptualized mainly as an individually driven activity (self-regulated learning) in a collective context, but does not look at how collective knowledge is created. Engeström's (2001) expansive learning theory is one that effectively connects knowledge creation and learning. Originating from Activity Theory, there is naturally a focus on contradictions introduced by new work practices (e.g. Ripamonti and Galuppo 2016), or on more explicit change management programs, like the change laboratory method (Sannino et al. 2016). Normalisation Process Theory has a similar focus on implementing and institutionalizing new work practices (May and Finch 2009). Group processes produce patterns of those new practices, and these are implemented through collective action, cognitive participation and reflexive monitoring. Our work offers some of the knowledge practices that could be observed in expansive learning, or normalization processes, for example co-creation processes as part of the generation of patterns, or scaffolding and knowledge appropriation that would be observed in cognitive participation or in reflexive monitoring.

Our model also addresses processes of innovation adoption within workplace learning. The knowledge appropriation model extends our understanding of how individual, collaborative and collective processes of knowledge conversion interact with each other to enable practice-based innovation (Ellström 2010), or employeedriven innovation (Lundkvist and Gustavsson 2018). Maturation, scaffolding and appropriation practices offer a distinction of the spiral model of organizational knowledge creation (Nonaka and Takeuchi 1995) and help to explain how organizations objectify emergent knowledge that is subjective to the context of creation (Nonaka and Toyama 2007) and then apply it elsewhere "on the ground".

Finally, we see good potential to apply the model in the context of designing information and communication technology (ICT) which to a large extent mediates today's work (Billett and Choy 2013). The impact of these technologies was clearly visible in the cases reported above. We found that mobile devices used in the context of work were contributing to collaboration and knowledge sharing (Waizenegger et al. 2016). Triggered by the ubiquity of mobile and social technologies, organizations are now trying to more effectively support processes around dealing with knowledge by establishing "social knowledge environments" (Pawlowski et al. 2014) through which many of the practices we have suggested can be supported, such as co-creation of artefacts, creating awareness of emergent knowledge, or social validation. Moreover, as ICT environments grow more and more "intelligent" and take over intellectual tasks, we will be evidencing a division of labor between those intelligent systems and human professionals. In a recent analysis, we used the knowledge appropriation model to explain how knowledge structures emerge and guide individual learning when such intelligent ICT tools are employed in work contexts (Ley 2019).

\section{Limitations of the Model}

We are aware of the fact that putting different models together as we have done always runs the risk of incommensurate conceptualizations being combined. And while we have 
taken care that the models we draw on (maturation, scaffolding) have all originated from a social learning perspective, questions remain whether, in practice, processes of co-creation can be very well differentiated from scaffolding. For social learning scholars, the knowledge appropriation practices we have proposed may also seem like a departure from sociocultural understanding of knowledge as a social constructive process and instead foreground representational ideas of knowledge. The details of such debate need to be left for another occasion, but we would agree that caution needs to be taken in the interpretation of these terms. In specifying knowledge appropriation practices, it was certainly our intention to emphasize the important mediational character artefacts have in connecting individual knowing and collective (cultural) knowledge practices.

A further limitation of the current model is that some of its parts have stronger empirical support than others. For example, the knowledge maturation model has been validated elsewhere (Maier and Schmidt 2015). The knowledge appropriation practices, on the other hand, are based mainly on exploratory qualitative evidence. Generalizability of the findings is limited for three reasons. First, the study was focused on the construction industry, and there might be additional practices relevant in other sectors of industry that we have not encountered in the construction industry. Second, our data was collected from small and medium-sized enterprises. There might be different or additional practices in large companies with well-established formal innovation management processes, or in public administration. Thirdly, a limitation may lie in the cross-sectional, rather than longitudinal focus of the interviews where we discussed concrete examples of knowledge creation in daily work practices. However, several practices, such as fading (e.g. Smith 2003) or standardizing (e.g. Maier and Schmidt 2015) might need more time to unfold. We included them in the model as they are widely covered in the previous literature.

The studies mentioned in the previous section (e.g. Leoste et al. 2019) as well as future work need to show whether the different perspectives that we have brought together can be productively combined, and whether all of the model components have additional explanatory capability that warrant their inclusion in the model.

Acknowledgements This research has been supported by the European Community under FP7 through the project Learning Layers (http://results.learning-layers.eu, grant no. 318209), and under Horizon 2020 through the CEITER project (http://ceiter.tlu.ee, grant no. 669074).

\section{Compliance with Ethical Standards}

Conflict of Interest The authors declare that they have no conflict of interest.

Open Access This article is distributed under the terms of the Creative Commons Attribution 4.0 International License (http://creativecommons.org/licenses/by/4.0/), which permits unrestricted use, distribution, and reproduction in any medium, provided you give appropriate credit to the original author(s) and the source, provide a link to the Creative Commons license, and indicate if changes were made.

\section{References}

Barrett, M., Cappleman, S., Shoib, G., \& Walsham, G. (2004). Learning in knowledge communities: Managing technology and context. European Management Journal, 22(1), 1-11. https://doi.org/10.1016/J.EMJ.2003.11.019. 
Billett, S. (2002). Toward a workplace pedagogy: Guidance, participation, and engagement. Adult Education Quarterly, 53(1), 27-43. https://doi.org/10.1177/074171302237202.

Billett, S., \& Choy, S. (2013). Learning through work: Emerging perspectives and new challenges. Journal of Workplace Learning, 25(4), 264-276. https://doi.org/10.1108/13665621311316447.

Boud, D., \& Middleton, H. (2003). Learning from others at work: Communities of practice and informal learning. Journal of Workplace Learning, 15(5), 194-202. https://doi.org/10.1108/13665620310483895.

Crossan, M. M., Lane, H. W., \& White, R. E. (1999). An organizational learning framework: From intuition to institution. Academy of Management Review, 24(3), 522-537. https://doi.org/10.5465/amr.1999.2202135.

Donald, M. (1991). Origins of the modern mind: Three stages in the evolution of culture and cognition. Cambridge: Harvard University Press.

Ellström, P.-E. (2010). Practice based innovation: A learning perspective. Journal of Workplace Learning, 22(1/2), 27-40. https://doi.org/10.1108/13665621011012834.

Engeström, Y. (2001). Expansive learning at work: Toward an activity theoretical reconceptualization. Journal of Education and Work, 14(1), 133-156. https://doi.org/10.1080/13639080123238.

Hollan, J., Hutchins, E., \& Kirsh, D. (2000). Distributed cognition: Toward a new foundation for humancomputer interaction research. ACM Transactions on Computer-Human Interaction, 7(2), 174-196. https://doi.org/10.1145/353485.353487.

Kimmerle, J., Cress, U., \& Held, C. (2010). The interplay between individual and collective knowledge: Technologies for organisational learning and knowledge building. Knowledge Management Research \& Practice, 8(1), 33-44. https://doi.org/10.1057/kmrp.2009.36.

Kogut, B., \& Zander, U. (1992). Knowledge of the firm, combinative capabilities, and the replication of technology. Organization Science, 3(3), 383-397. https://doi.org/10.1287/orsc.3.3.383.

Lave, J., \& Wenger, E. (1991). Situated learning: Legitimate peripheral participation. Cambridge: Cambridge University Press.

Leoste, J., Tammets, K., \& Ley, T. (2019). Co-creation of learning designs: Analyzing knowledge appropriation in teacher training programs. In Companion Proceeding of the 14th European Conference on Technology-enhanced Learning (EC-TEL) (in press). Aachen: CEUR Workshop Proceedings.

Ley, T. (2019). Knowledge structures for integrating working and learning: A reflection on a decade of learning technology research for workplace learning. British Journal of Educational Technology, in press. https://doi.org/10.1111/bjet.12835.

Ley, T., Seitlinger, P., \& Pata, K. (2016). Patterns of meaning in a cognitive ecosystem: Modeling stabilization and enculturation in social tagging systems. In U. Cress, H. Jeong, \& J. Moskaliuk (Eds.), Mass collaboration and education (pp. 143-163). Heidelberg: Springer.

Littlejohn, A., Margaryan, A., \& Milligan, C. (2012). Charting collective knowledge: Supporting self-regulated learning in the workplace. Journal of Workplace Learning, 24(3), 226-238. https://doi.org/10.1108/13665621211209285.

Lundkvist, A., \& Gustavsson, M. (2018). Conditions for employee learning and innovation Interweaving competence development activities provided by a workplace development programme with everyday work activities in SMEs. Vocations and Learning, 11(1), 45-63. https://doi.org/10.1007/s12186-017-9179-6.

Maier, R., \& Schmidt, A. (2015). Explaining organizational knowledge creation with a knowledge maturing model. Knowledge Management Research \& Practice, 13(4), 361-381. https://doi.org/10.1057 /kmrp.2013.56.

May, C., \& Finch, T. (2009). Implementing, embedding, and integrating practices: An outline of normalization process theory. Sociology, 43(3), 535-554. https://doi.org/10.1177/0038038509103208.

Mayring, P. (2014). Qualitative content analysis - Theoretical foundation, basic procedures and software solution. Klagenfurt, Austria: Social Science Open Access Repository.

Nardi, B. A. (1996). Context and consciousness: Activity theory and human-computer interaction. Cambridge: MIT Press.

Nonaka, I., \& Takeuchi, H. (1995). The knowledge-creating company: How japanese companies create the dynamics of innovation. The knowledge-creating company: How Japanese companies create the dynamics of innovation. New York: Oxford University Press.

Nonaka, I., \& Toyama, R. (2007). Why do firms differ? The theory of the knowledge-creating firm. In K. Ichijo \& I. Nonaka (Eds.), Knowledge creation and management: New challenges for managers (pp. 1331). Oxford, UK: Oxford University Press.

Nonaka, I., Von Krogh, G., \& Voelpel, S. (2006). Organizational knowledge creation theory: Evolutionary paths and future advances. Organization Studies, 27(8), 1179-1208. https://doi.org/10.1177 /0170840606066312. 
Paavola, S., \& Hakkarainen, K. (2014). Trialogical approach for knowledge creation. In S. C. Tan, H. J. So, \& J. Yeo (Eds.), Knowledge creation in education (pp. 53-73). Singapore: Springer. https://doi.org/10.1007 /978-981-287-047-6 4.

Paavola, S., Lipponen, L., \& Hakkarainen, K. (2004). Models of innovative knowledge communities and three metaphors of learning. Review of Educational Research, 74(4), 557-576. https://doi.org/10.3102/00346543074004557.

Pawlowski, J. M., Bick, M., Martensen, M., Peinl, R., Thalmann, S., Maier, R., et al. (2014). Social knowledge environments. Business \& Information Systems Engineering., 6, 81-88. https://doi.org/10.1007/s12599-014-0318-4.

Ripamonti, S. C., \& Galuppo, L. (2016). Work transformation following the implementation of an ERP system: An activity-theoretical perspective. Journal of Workplace Learning, 28(4), 206223. https://doi.org/10.1108/JWL-01-2016-0005.

Rogoff, B. (1995). Observing sociocultural activity on three planes: Participatory appropriation, guided participation, and apprenticeship. In J. V. Wertsch, P. del Rio, \& A. Alvarez (Eds.), Pedagogy and practice: Culture and identities (pp. 139-164). Cambridge: Cambridge University Press.

Sannino, A., Engeström, Y., \& Lahikainen, J. (2016). The dialectics of authoring expansive learning: Tracing the long tail of a change laboratory. Journal of Workplace Learning, 28(4), 245-262. https://doi.org/10.1108/JWL-01-2016-0003.

Schäper, S., \& Thalmann, S. (2015). Addressing challenges for informal learning in networks of organizations. In J. Becker, J. vom Brocke, \& M. de Marco (Eds.), Twenty-Third European Conference on Information Systems (ECIS). AIS Electronic Library (AISeL).

Siadaty, M., Gašević, D., \& Hatala, M. (2016). Measuring the impact of technological scaffolding interventions on micro-level processes of self-regulated workplace learning. Computers in Human Behavior, 59, 469-482. https://doi.org/10.1016/j.chb.2016.02.025.

Smith, P. J. (2003). Workplace learning and flexible delivery. Review of Educational Research, 73(1), 53-88.

Stahl, G. (2013). Learning across levels. International Journal of Computer-Supported Collaborative Learning, 8(1), 1-12. https://doi.org/10.1007/s11412-013-9169-0.

Tammets, K., Laanpere, M., Pata, K., \& Ley, T. (2013). Identifying problem-based scaffolding patterns in an online forum for construction professionals. In D. Hernández-Leo, T. Ley, R. Klamma, \& A. Harrer (Eds.), Proceedings of the 8th European Conference on Technology-enhanced Learning (EC-TEL) (pp. 526-531). Heidelberg: Springer. https://doi.org/10.1007/978-3-642-40814-4_50

Twidale, M. B. (2005). Over the shoulder learning: Supporting brief informal learning. Computer Supported Cooperative Work (CSCW), 14(6), 505-547. https://doi.org/10.1007/s10606-005-9007-7.

Vygotsky, L. S. (1978). Mind in society: The development of higher mental process. Cambridge: Harvard University Press.

Waizenegger, L., Thalmann, S., Sarigianni, C., Eckhardt, A., Kolb, D., Ulrich, R. (2016). From isolation to collaboration - How the increasing diffusion of mobile devices has changed practices of knowledge sharing in non-office settings. In J. Becker, J. vom Brocke, \& M. de Marco (Eds.), Proceedings of the 24th European Conference on Information Systems, Istanbul, Turkey. AIS Electronic Library (AISeL). Retrieved from http://aisel.aisnet.org/ecis2016_rp/62

Wenger, E. (2004). Communities of practice : Learning, meaning, and identity. Cambridge University Press. Wood, D., Bruner, J. S., \& Ross, G. (1976). The role of tutoring in problem solving. Journal of Child Psychology and Psychiatry, 17(2), 89-100. https://doi.org/10.1111/j.14697610.1976.tb00381.x.

Publisher's Note Springer Nature remains neutral with regard to jurisdictional claims in published maps and institutional affiliations.

Tobias Ley is a Professor of Learning Analytics and Educational Innovation at the School of Educational Sciences at Tallinn University where he leads the Center of Excellence in Educational Innovation. His research interests are in technology-enhanced learning, knowledge management, workplace learning and human computer interaction. He received his $\mathrm{PhD}$ in Psychology and Knowledge Management from the University of Graz. Tobias has had leading roles in a number of large-scale EU funded projects on workplace learning and has earned best paper awards (Journal of Knowledge Management and ECTEL) and a European research award for Vocational Education and Training. He is a member of the editorial board of the IEEE Transactions on Learning Technologies. 
Ronald Maier is Professor of Information Systems and heads the Department of Information Systems, Production and Logistics Management, University of Innsbruck, Austria. His research interests include collaboration engineering, connectivity, crowdsourcing, digital change and knowledge management. His research has appeared in books such as Knowledge Management Systems or Knowledge Management in Digital Change and journals such as Journal of Management Information Systems, Journal of Strategic Information Systems, Business \& Information Systems Engineering, Computers in Human Behavior, IEEE Transactions on Learning Technologies and Journal of Knowledge Management.

Stefan Thalman is a Professor of Business Analytics at the University of Graz and director of the Center for Business Analytics and Data Science. He received his Ph.D. in Information Systems and a habilitation degree from University of Innsbruck, Austria. His main research interests are in the areas of business analytics, technology enhanced learning, data driven decision support, knowledge management and knowledge protection.

Lena Waizenegger is a Lecturer in Business Information Systems at the Auckland University of Technology, New Zealand. Lena received her PhD in Information Systems from the University of Innsbruck, Austria in July 2017. Her main research areas are ubiquitous connectivity, the impact of conversational agents on the human workforce, and digital disconnection.

Kai Pata received $\mathrm{PhD}$ in Education in Turku University. She is a senior researcher and the head of the Technology-enhanced Learning workgroup at Tallinn University, School for Digital Technologies. Her research interests have been scaffolding learning with digital supports, workplace learning and distributed cognition.

Adolfo Ruiz-Calleja received his $\mathrm{MSc}$ and $\mathrm{PhD}$ degrees in telecommunications engineering from the University of Valladolid, Spain, in 2007 and 2013 respectively. He is currently working as a researcher in the Center for Educational Technology at Tallinn University. His research interests include learning analytics, distributed systems, data management and their application in formal and informal learning.

\section{Affiliations}

\section{Tobias Ley ${ }^{1} \cdot$ Ronald Maier $^{2} \cdot$ Stefan Thalmann $^{3} \cdot$ Lena Waizenegger $^{4} \cdot$ Kai Pata $^{5}$. Adolfo Ruiz-Calleja ${ }^{5}$}

1 School of Educational Sciences, Tallinn University, Uus Sadama 5, 10125 Tallinn, Estonia

2 Department of Information Systems, Production and Logistics Management, University of Innsbruck, Innsbruck, Austria

3 Center for Business Analytics and Data Science, University of Graz, Graz, Austria

4 Department of Business Information Systems, Auckland University of Technology, Auckland, Australia

5 School of Digital Technologies, Tallinn University, Tallinn, Estonia 